\title{
Extensive Noachian fluvial systems in Arabia Terra: Implications for early martian climate
}

\section{Supplementary Material}

\section{J. M. Davis, M. Balme, P. M. Grindrod, R. M. E. Williams, S. Gupta}

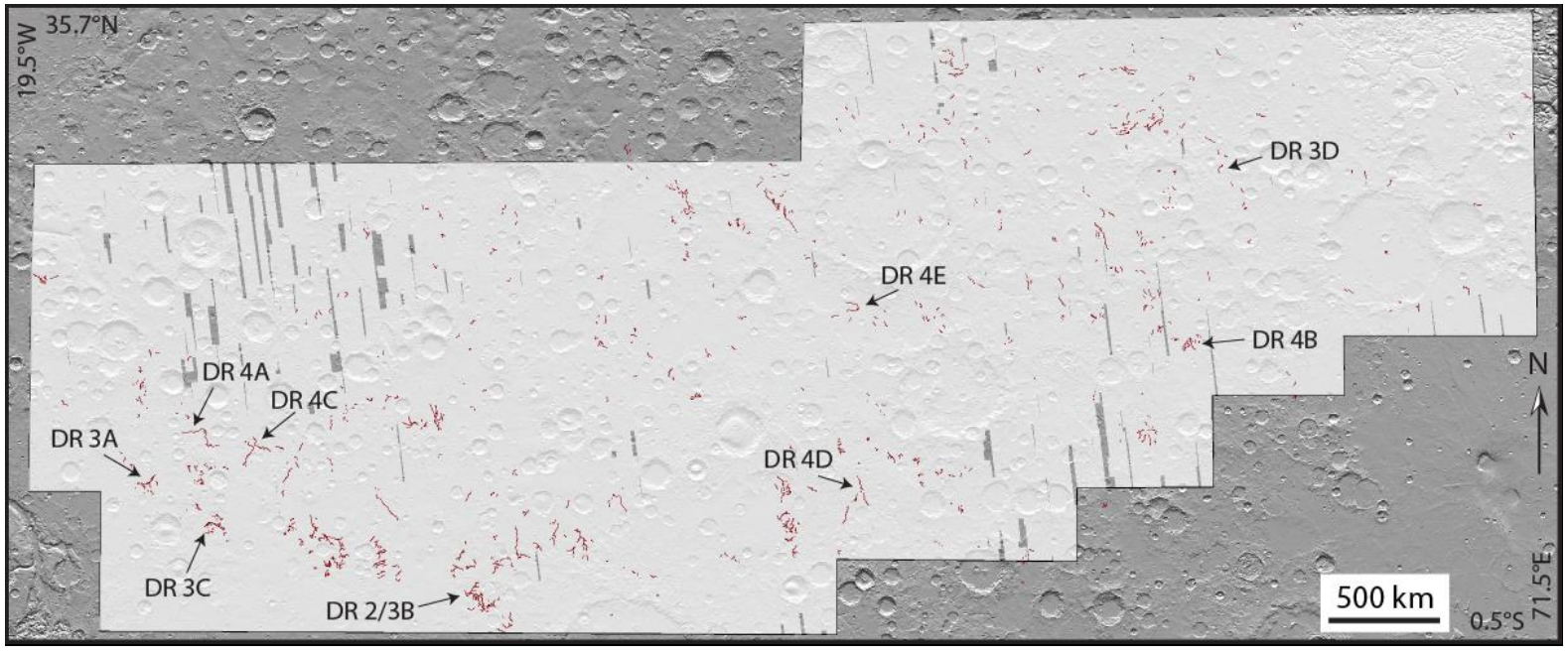

Figure DR 1: Mars Reconnaissance Orbiter (MRO) Context Camera (CTX; 6 m/pixel; Malin et al., 2007) coverage of study area in Arabia Terra. The white shaded area shows the CTX image footprints that were examined, where the image coverage is near $100 \%$. Inverted channels are shown in red. Context locations are also shown for all supplementary figures.

\begin{tabular}{lr}
\hline Total observed channel length (from CTX data; $~ 6 \mathrm{~m} / \mathrm{pixel})$ & $\sim 17,400 \mathrm{~km}$ \\
Highest stream order & 7 \\
Longest continuous segment & $\sim 200 \mathrm{~km}$ \\
Maximum channel width & $\sim 1500 \mathrm{~m}$ \\
Maximum channel height above surrounding terrain & $\sim 60 \mathrm{~m}$ \\
Minimum channel elevation & $\sim-2400 \mathrm{~m}$ \\
Maximum channel elevation & $\sim+1250 \mathrm{~m}$ \\
\hline
\end{tabular}

Table DR 1: Summary table of Arabia Terra inverted channel characteristics. 


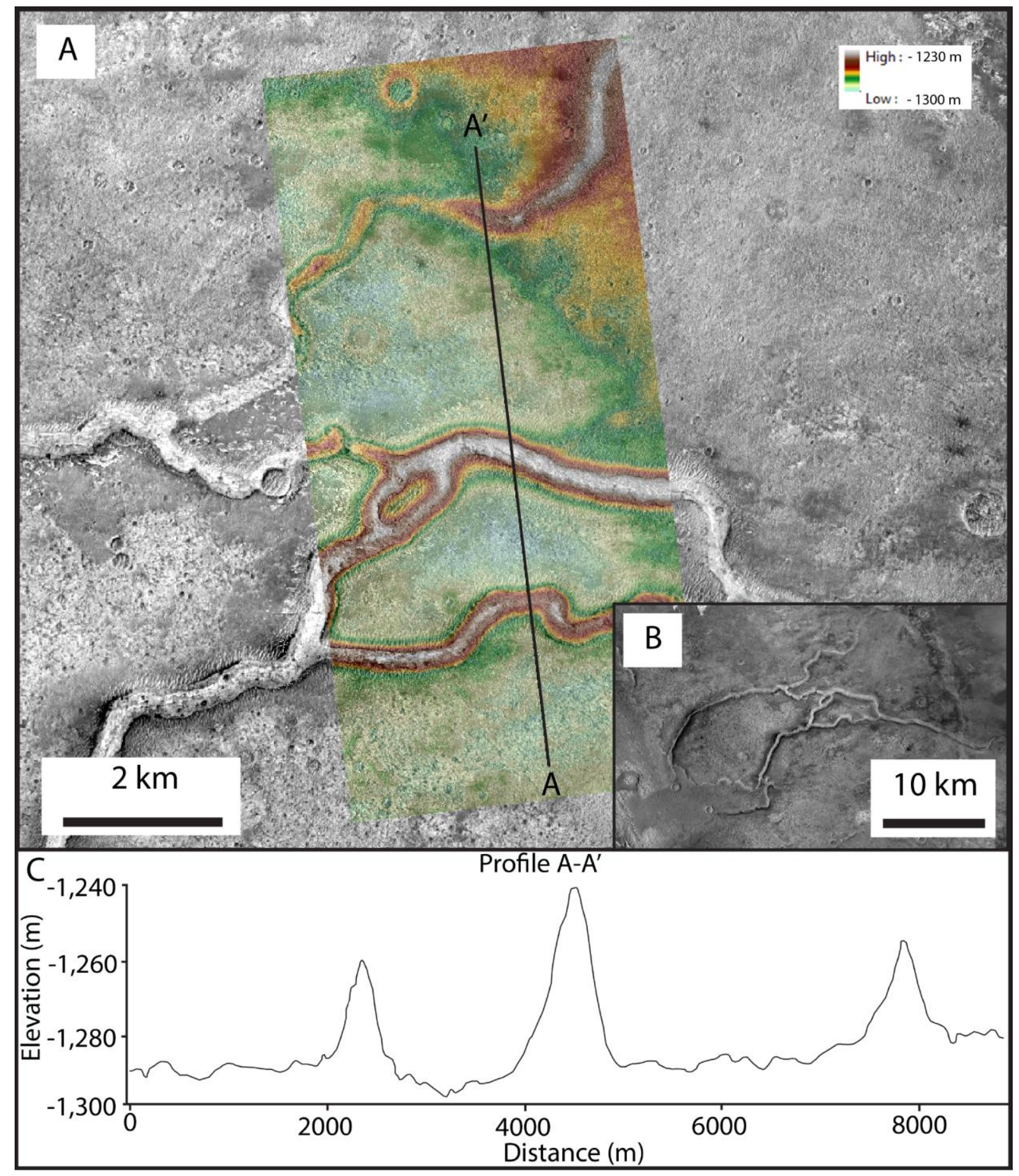

Figure DR 2: (A) MRO High Resolution Imaging Science Experiment (HiRISE; $25 \mathrm{~cm} / \mathrm{pixel}$; McEwen et al., 2007) resolution digital elevation model (DEM; $\sim 1 \mathrm{~m} /$ pixel) showing an inverted channel system. The DEM was produced according to the method of Kirk et al. (2008). (B) CTX image mosaic for this inverted channel system. (C) Topographic profile (A-A') of the inverted channel system extracted from HiRISE DEM above. The inverted channels here are up to $\sim 60 \mathrm{~m}$ high and almost $1 \mathrm{~km}$ in width. Elsewhere, inverted channels are typically $\sim 10-60$ $\mathrm{m}$ high. However, these values do not represent former channel depth, but instead give an indication of the minimum thickness of marginal alluvium that was removed prior to etched 
unit emplacement. Assuming the channels were emplaced and fully inverted between the midto late Noachian, a period of $200 \mathrm{Ma}$, the average erosion rate was therefore $\sim 50-300 \mathrm{~nm} / \mathrm{yr}$. This is comparable to the low end of values previously estimated for erosion rates during the mid- to late Noachian ( 100s to 1000s of nm/yr; Golombek et al., 2006).

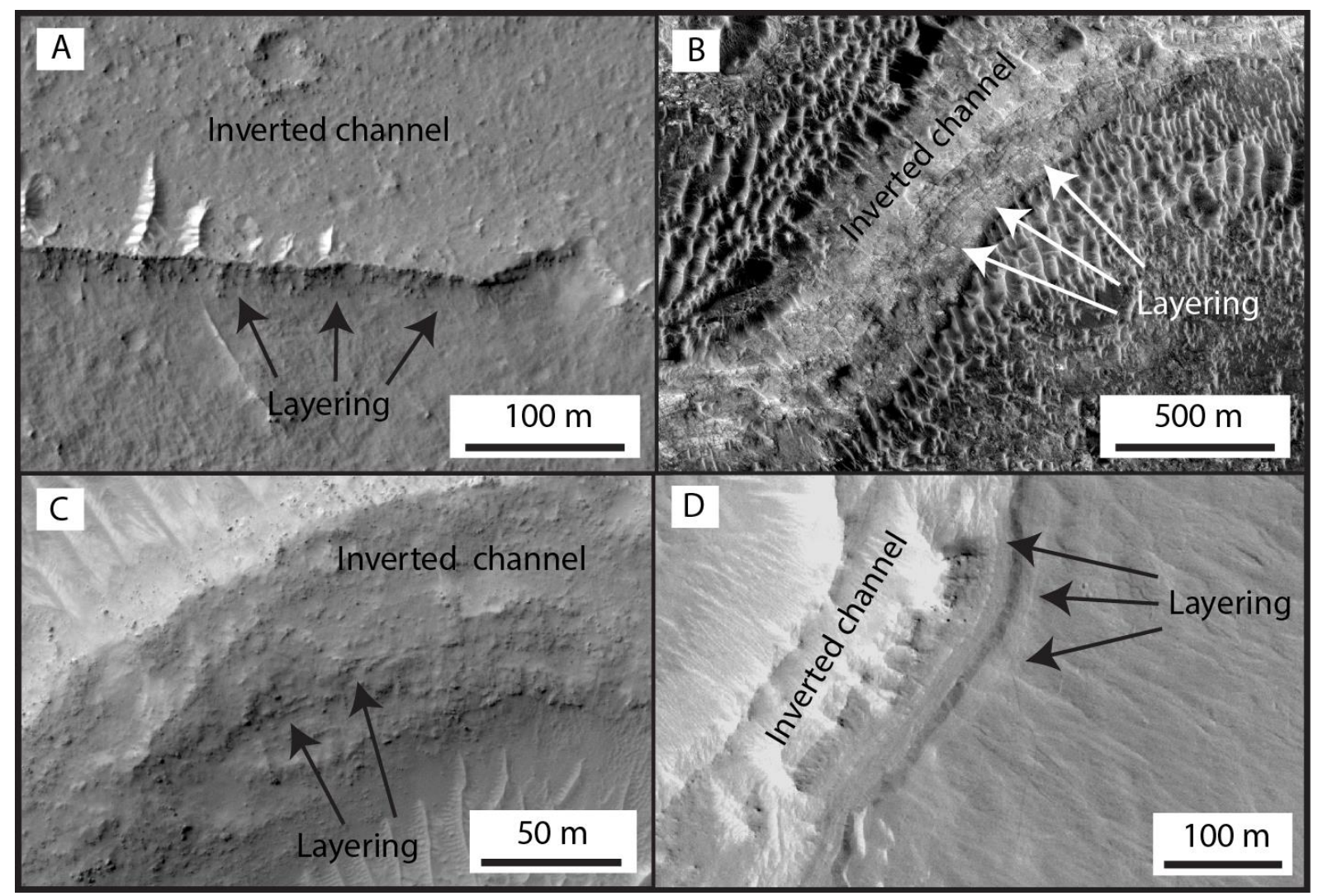

Figure DR 3: HiRISE images show sub-horizontal meter to decameter-scale internal layering exposed at the edges of inverted channels, throughout Arabia Terra. The layering is consistent with the inverted channels being composed of indurated channel floor sediment.

Figure DR 4 (overleaf): Inverted channels systems across Arabia Terra; (A) Near continuous inverted channel in the east becomes more segmented towards the west, where it is nearly level with the adjacent material; (B) Branching and sinuous inverted channels which terminate in an infilled crater, which could be an exhumed paleolake deposit, or alternatively, infilling etched material; see also Fassett and Head, 2007, Grant and Schultz, 1990; (C) Inverted channel with possible capping unit; (D and E) Distal ends of Naktong and Scamander Valles, respectively, where inverted channels are present within the negative relief valley networks. 


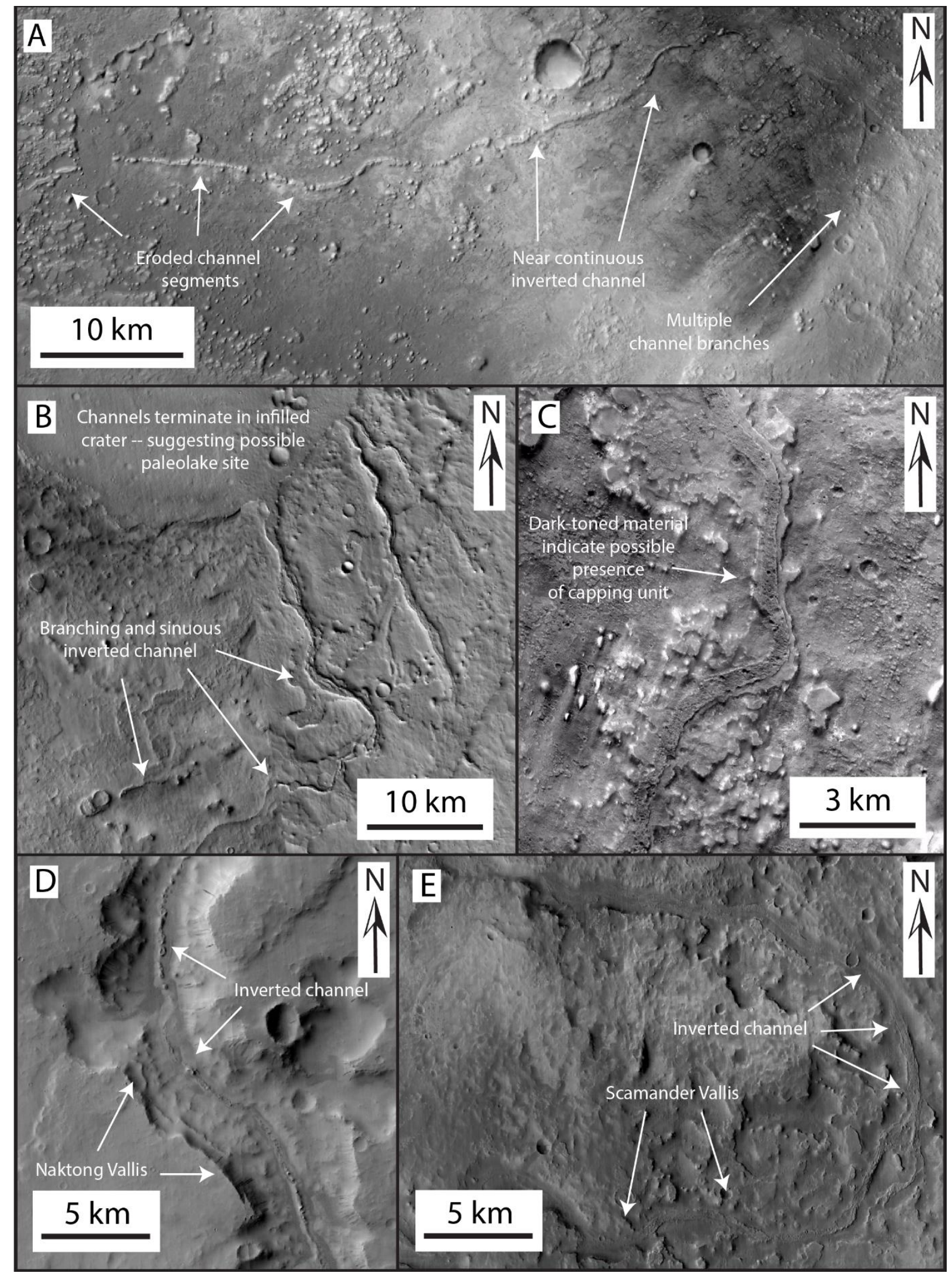




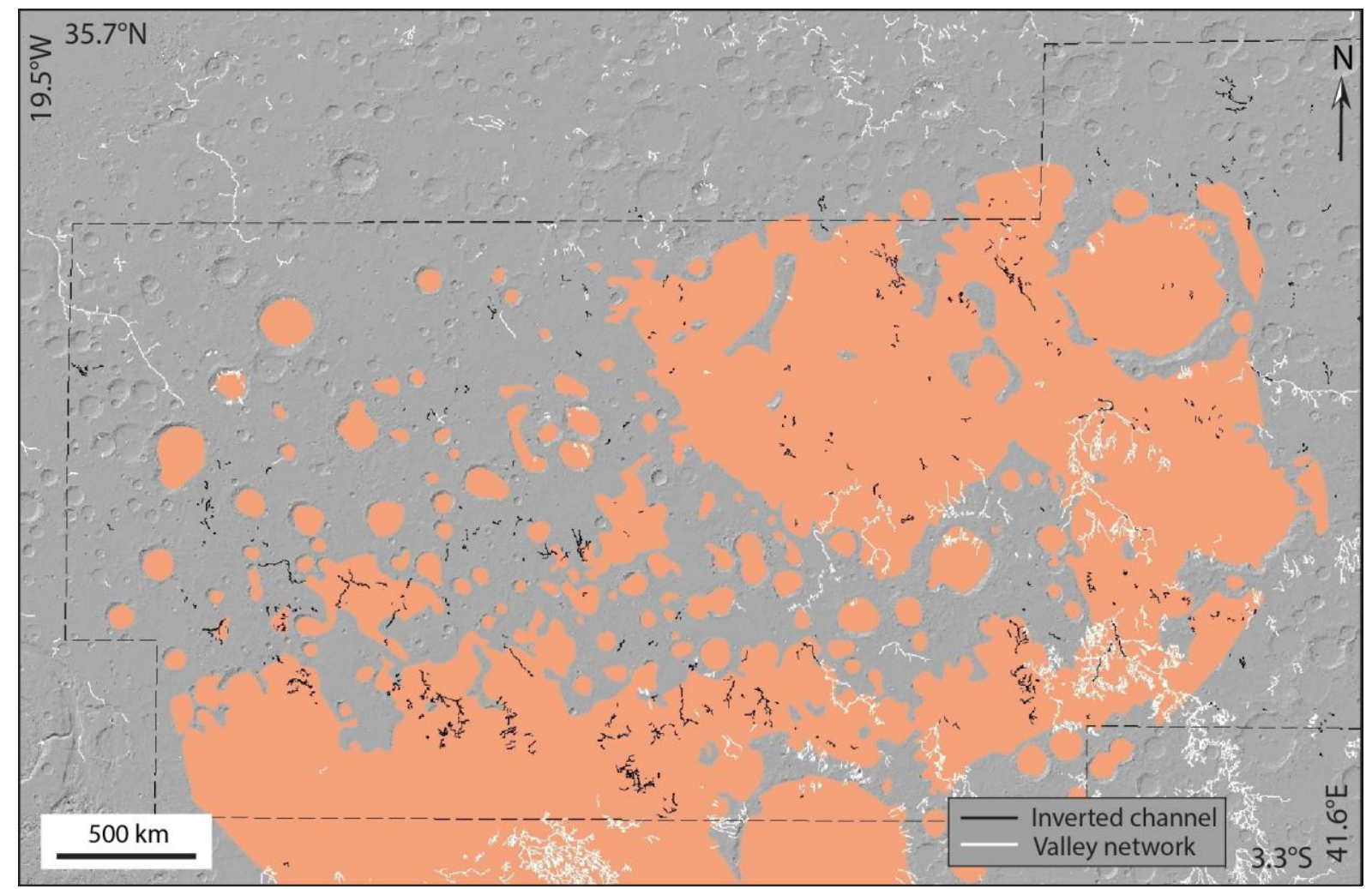

Figure DR 5: Paleo-surface showing former extent of etched units (orange) by Zabrusky et al. (2012; Figure 9, surface a) overlaid on MOLA hillshade map of western Arabia Terra. $~ 80 \%$ of inverted channels (solid black lines) are spatially associated with this surface, suggesting that the etched units have protected the inverted channels from erosion. Adapted from Zabrusky et al. (2012). 
A) Mid- to late Noachian

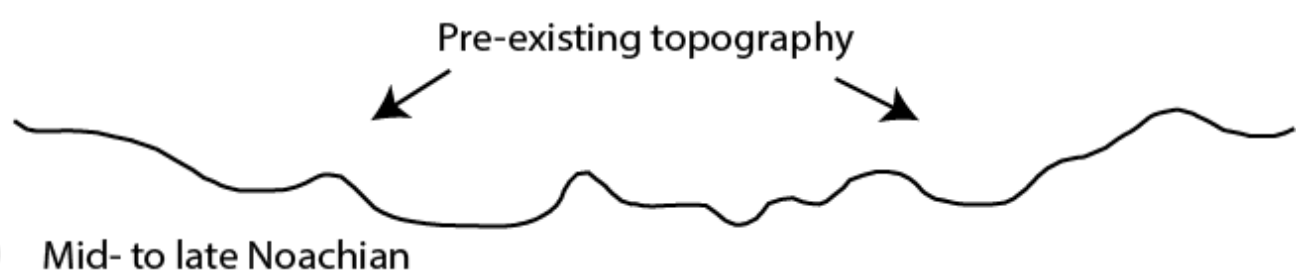

B) Mid- to late Noachian

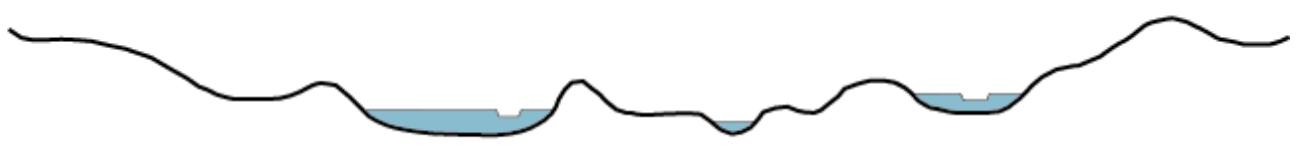

C) Mid- to late Noachian

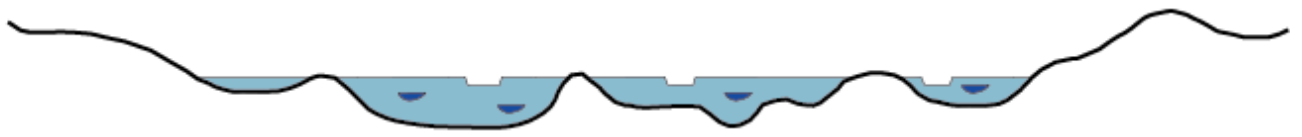

D) Late Noachian?

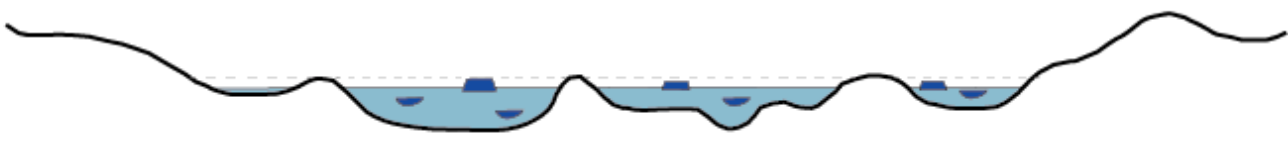

E) Late Noachian/early Hesperian

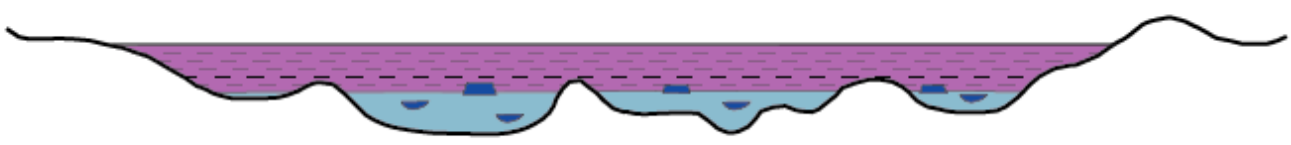

F) Amazonian

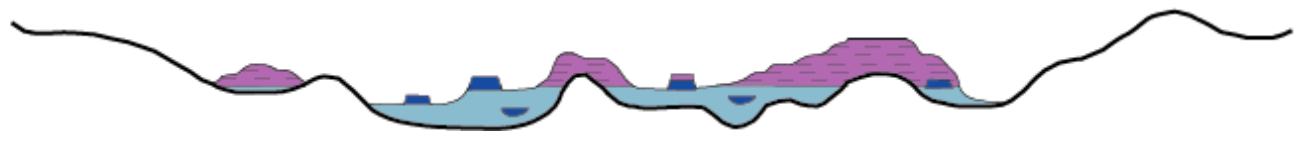

Figure DR 6: Possible sequence of inverted channel formation; A) Pre-existing topography; B) Sediment deposition in topographic lows, possibly in isolated alluvial plains, and formation of discrete fluvial channels; C) Continued aggradation, merging of smaller alluvial systems, and burial of older channels; D) Waning of fluvial activity, ongoing eolian abrasion leaves indurated channel sediment preserved in positive relief; E) Burial and protection of inverted channels by etched units; F) Regional deflation removes etched units and exposes inverted channels to the surface environment. 


\begin{tabular}{|c|c|c|}
\hline Figure & Instrument & Image ID \\
\hline Fig. 1 & MOLA* & Global mosaic derived product \\
\hline Fig. $2 \mathrm{~A}$ & CTX & $\begin{array}{l}\text { B03_010829_1892_XI_09N012W; } \\
\text { B01_009840_1885_XN_08N010W; } \\
\text { D09_030714_1876_XI_07N011W; } \\
\text { G23_027180_1889_XI_08N011W }\end{array}$ \\
\hline Fig. 2B & CTX & $\begin{array}{l}\text { B10_013532_1835_XN_03N006W; } \\
\text { D04_028881_1843_XI_04N007W; } \\
\text { B03_010697_1875_XI_07N007W }\end{array}$ \\
\hline Fig. 3A & THEMIS nighttime** & Global mosaic derived product \\
\hline Fig. 3B & HiRISE & PSP_004091_1845 \\
\hline Fig. 4 & CTX & $\begin{array}{l}\text { B19_017012_1877_XN_07N333W; } \\
\text { D01_027627_1876_XI_07N333W }\end{array}$ \\
\hline Fig. DR 1 & MOLA (hillshade) & Global mosaic derived product \\
\hline Fig. DR 2A & CTX and HiRISE & $\begin{array}{l}\text { ESP_012714_1815; } \\
\text { ESP_012714_1815; } \\
\text { P04_002627_1808_XN_00N352W; } \\
\text { G23_027298_1822_XI_02N352W }\end{array}$ \\
\hline Fig. DR 2B & CTX & $\begin{array}{l}\text { P04_002627_1808_XN_00N352W; } \\
\text { G23_027298_1822_XI_02N352W; } \\
\text { P07_003616_1815_XI_01N353W }\end{array}$ \\
\hline Fig. DR 3A & HiRISE & ESP_036384_1880 \\
\hline Fig. DR 3B & HiRISE & ESP_012648_1815 \\
\hline Fig. DR 3C & HiRISE & ESP_033586_2065 \\
\hline Fig. DR 3D & HiRISE & ESP_022221_1850 \\
\hline Fig. DR 4A & CTX & $\begin{array}{l}\text { P22_009774_1916_XN_11N009W; } \\
\text { B17_016143_1909_XI_10N008W; } \\
\text { B17_016288_1919_XN_11N008W; } \\
\text { B06_011831_1914_XN_11N008W }\end{array}$ \\
\hline Fig. DR 4B & CTX & $\begin{array}{l}\text { P07_003588_1958_XN_15N310W; } \\
\text { P03_002032_1959_XN_15N310W }\end{array}$ \\
\hline Fig. DR 4C & CTX & $\begin{array}{l}\text { P18_008139_1900_XN_10N004W; } \\
\text { P09_004023_1915 }\end{array}$ \\
\hline Fig. DR 4D & CTX & P19_008375_1874_XN_07N329W \\
\hline Fig. DR 4E & CTX & $\begin{array}{l}\text { P15_006872_1983_XI_18N329W; } \\
\text { P13_006160_1977_XN_17N330W }\end{array}$ \\
\hline Fig. DR 5 & MOLA (hillshade) & Global mosaic derived product \\
\hline
\end{tabular}

Table DR 2: Instrument and image ID numbers used in all figures.

*Smith et al., 2001

**Christensen et al., 2004 


\section{References:}

Christensen, P.R., et al., 2004, The Thermal Emission Imaging System (THEMIS) for the Mars 2001 Odyssey mission: Space Science Reviews, v. 110, p. 85-130, doi: 10.1023 /B:SPAC.0000021008.16305.94.

Fassett, C.I., and Head, J.W., III, 2007, Layered mantling deposits in northeast Arabia Terra, Mars: Noachian-Hesperian sedimentation, erosion, and terrain inversion: Journal of Geophysical Research, v. 112, E08002, doi: 10.1029/2006JE002875.

Golombek, M.P., et al., 2006, Erosion rates at the Mars Exploration Rover landing sites and long-term climate change on Mars: Journal of Geophysical Research, v. 111, E12S10, doi: 10.1029/2006JE002754.

Grant, J.A., and Schultz, P.H., 1990, Gradational epochs on Mars: Evidence from WestNorthwest of Isidis Basin and Electris: Icarus, v. 84, p. 166-195, doi: 10.1016/00191035(90)90164-5.

Hynek, B.M., Beach, M., and Hoke, M.R.T., 2010, Updated global map of Martian valley networks and implications for climate and hydrologic processes: Journal of Geophysical Research, v. 115, E09008, doi: 10.1029/2009JE003548.

Kirk, R.L., et al., 2008, Ultrahigh resolution topographic mapping of Mars with MRO HiRISE stereo images: Meter-scale slopes of candidate Phoenix landing sites: Journal of Geophysical Research, v. 113, E00A24, doi: 10.1029/2007JE003000.

Malin, M.C., et al., 2007, Context Camera Investigation on board the Mars Reconnaissance Orbiter: Journal of Geophysical Research, v. 112, E05S04, doi: 10.1029/2006JE002808.

McEwen, A.S., et al., 2007, Mars Reconnaissance Orbiter's High Resolution Imaging Science Experiment (HiRISE): Journal of Geophysical Research, v. 112, E05S02, doi: 10.1029/2005JE002605.

Smith, D.E., et al., 2001, Mars Orbiter Laser Altimeter: Experiment summary after the first year of global mapping of Mars: Journal of Geophysical Research, v. 106, p. 23,68923,722, doi: $10.1029 / 2000 J E 001364$.

Zabrusky, K., Andrews-Hanna, J.C., and Wiseman, S.M., 2012, Reconstructing the distribution and depositional history of the sedimentary deposits of Arabia Terra, Mars: Icarus, v. 220, p. 311-330, doi: 10.1016/j.icarus.2012.05.007. 